\title{
The effect of the recombination mechanisms location on the temperature sensitivity of thin-film photovoltaic cells
}

\author{
N. Kata ${ }^{1, *}$, D. Diouf ${ }^{1}$, A. Darga ${ }^{2}$, and A. Seidou Maiga ${ }^{1}$ \\ ${ }^{1}$ Laboratoire Electronique, Informatique, Télécommunication et Energies Renouvelables, Université Gaston Berger, Saint-Louis, \\ Senegal \\ ${ }^{2}$ GeePs-CentraleSupelec, Laboratoire de Génie Electrique et Electronique de Paris, Universités de Sorbonne, UPMC Université \\ Paris 06, UMR 8507, 91190 Gif sur Yvette, France
}

Received: 15 February 2019 / Received in final form: 10 July 2019 / Accepted: 5 September 2019

\begin{abstract}
Thin film solar cells temperature sensitivity and impact of the main recombination mechanism location are investigated in this paper. The main mechanisms in bulk and at the heterojunction interface are discriminated. Using a 1D simulation software, "Solar Cell Capacitance Simulator" (SCAPS), we observed a higher temperature coefficient of open circuit voltage $\left(V_{o c}\right)$ for cells with main recombination centers at the interface than the one with main recombination centers in volume. Furthermore, an LTSpice module model is used to visualize the effects of the recombination centers' location on the performance ratios of the modules. The results show more degradation for the ratios performance of cells with the main recombination mechanisms at the interface than those in volume.
\end{abstract}

Keywords: Temperature sensitivity / recombination mechanisms / ratios performance / thin film cells

\section{Introduction}

The weighted average cost of installed solar photovoltaic electricity dropped from $\$ 5 /$ Watt in 2009 to about $\$ 2 /$ Watt in 2015 [1]. This drop in cost helps to show that the new main challenge in this domain is to ensure the efficient operation of networks. In Africa, numerous projects are implemented for both large scale PV plants and stand-alone PV systems. However, in order to obtain a sustainable and reliable modules operation, the local climatic conditions should be taken into account. Temperature and dust are one of the climatic factors that significantly influence the performance of solar modules $[2,3]$. These two factors characterize most of sub-Saharan African countries. Even if the effect of dust can be eliminated by programmed cleaning, the reduction of the temperature impact depends on the solar cell quality. In an early work, Green studied the temperature sensitivity of photovoltaic cells [4]. He derived the general form of the temperature coefficient of the open circuit voltage $\left(V_{\mathrm{oc}}\right)$ of the $\mathrm{PV}$ cells. This coefficient depends on recombination mechanism in the cells. His findings have been refined for the case of radiative

\footnotetext{
* e-mail: kata.ndetigma@ugb.edu.sn
}

recombination in cells by Dupré [5]. Thin film solar cells can exhibit a higher defect density at the heterojunction interface than in the bulk of each junction layer due to lattice mismatch and defect segregation at the interface.

We examine the main recombination mechanisms location impact on the $V_{o c}$ temperature coefficient of thin film cells. Different thin film solar cells configurations with three technologies (copper indium gallium selenide (CIGS), Perovskite, silicon tandem) are investigated. We have gone one step further and checked over these cells' performance ratios in sub-Saharan African climatic conditions. The results are compared to the most used cell technology (crystalline silicon).

\section{Materials and methods}

Figure 1 summarizes the approach used in this study. The numerical simulations are performed using the 1D simulation software named "Solar Cell Capacitance Simulator" (SCAPS ver. 3.3.02). The solar cell architectures defined consist of transparent conductive oxide/ buffer/absorber/hole transport material. The basic physics and device parameters for the simulated cells are obtained from literature [6-8]. The parameters for cells heterojunction layers are summarized in Table 1 . In order to 


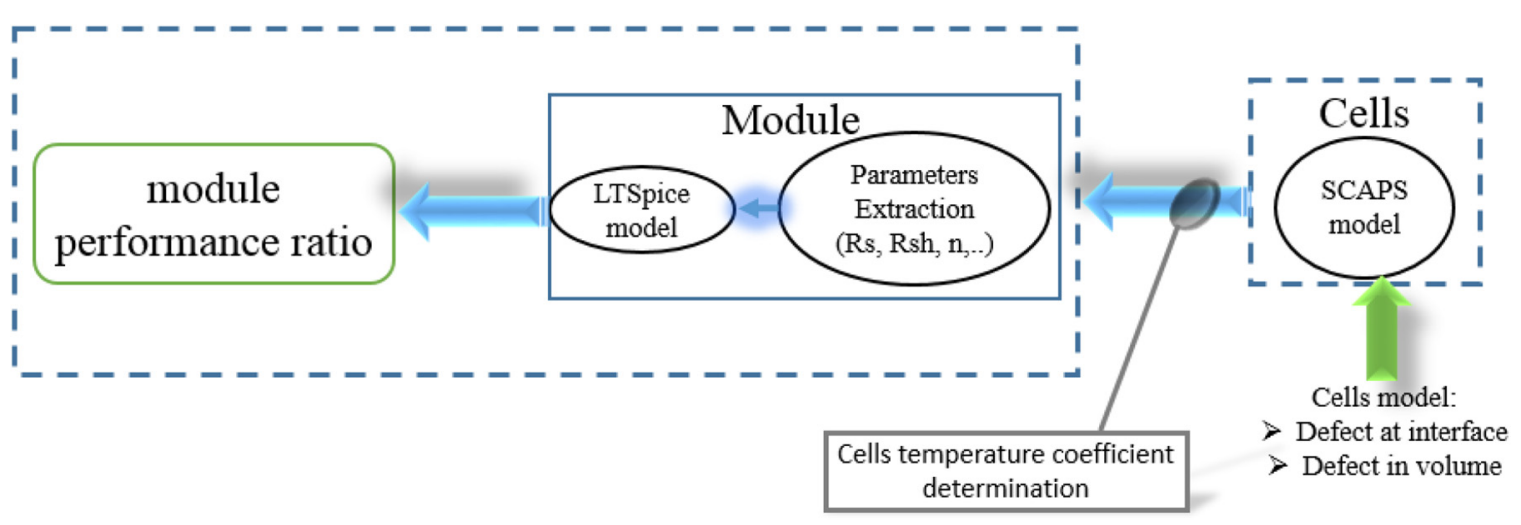

Fig. 1. Summary of the study approach.

Table 1. Parameters of the layers forming the heterojunction for each cell.

\begin{tabular}{|c|c|c|c|c|c|c|c|c|}
\hline \multirow{2}{*}{$\begin{array}{l}\text { Cells } \\
\text { Layers }\end{array}$} & \multicolumn{3}{|c|}{ Tandem-Si } & \multicolumn{2}{|c|}{ CIGS } & \multicolumn{3}{|c|}{ Perovskite } \\
\hline & a-Si:H (i) & $\mu c-S i(n)$ & a-Si:H (i) & CIGS & $\mathrm{CdS}$ & $\mathrm{TiO}_{2}$ & Perovskite & Spiro-HTM \\
\hline \multicolumn{9}{|l|}{ Parameters } \\
\hline$d(\mu \mathrm{m})$ & 0.01 & 200 & 0.01 & 1 & 0.1 & 0.05 & 0.323 & 0.350 \\
\hline$E_{\mathrm{g}}(\mu \mathrm{m})$ & 1.72 & 1.15 & 1.72 & 1.2 & 2.4 & 3.2 & 1.55 & 3 \\
\hline$\chi$ & 3.9 & 4 & 3.9 & 4.1 & 4 & 3.9 & 3.9 & 2.45 \\
\hline$\varepsilon$ & 11.9 & 11 & 11.9 & 10 & 10 & 9 & 6.5 & 3 \\
\hline$N_{\mathrm{c}}\left(\mathrm{cm}^{-3}\right)$ & $10^{20}$ & $2.8 \times 10^{19}$ & $10^{20}$ & $10^{19}$ & $10^{19}$ & $2.2 \times 10^{18}$ & $2.2 \times 10^{18}$ & $2.2 \times 10^{18}$ \\
\hline$N_{\mathrm{v}}\left(\mathrm{cm}^{-3}\right)$ & $10^{20}$ & $10^{19}$ & $10^{20}$ & $10^{19}$ & $10^{19}$ & $1.8 \times 10^{19}$ & $1.8 \times 10^{19}$ & $1.8 \times 10^{19}$ \\
\hline$\left(\mathrm{cm} \cdot \mathrm{s}^{-1}\right) v_{t h n}$ & $10^{7}$ & $10^{7}$ & $10^{7}$ & $10^{7}$ & $10^{7}$ & $10^{7}$ & $10^{7}$ & $10^{7}$ \\
\hline$\left(\mathrm{cm} \cdot \mathrm{s}^{-1}\right) v_{t h p}$ & $10^{7}$ & $10^{7}$ & $10^{7}$ & $10^{7}$ & $10^{7}$ & $10^{7}$ & $10^{7}$ & $10^{7}$ \\
\hline$\left(\mathrm{cm}^{2} \cdot \mathrm{s}^{-1}\right) \mu_{n}$ & 20 & 816 & 20 & 25 & 50 & 5 & 2 & $2 \times 10^{-4}$ \\
\hline$\left(\mathrm{cm}^{2} \cdot \mathrm{s}^{-1}\right) \mu_{p}$ & 5 & 480 & 5 & 10 & 25 & 5 & 2 & $2 \times 10^{-4}$ \\
\hline$N_{\mathrm{d}}$ & $10^{14}$ & $5 \times 10^{16}$ & $10^{14}$ & - & $5 \times 10^{17}$ & $2 \times 10^{19}$ & $10^{13}$ & - \\
\hline$N_{\mathrm{a}}$ & $10^{14}$ & - & $10^{14}$ & $4 \times 10^{16}$ & - & - & $10^{13}$ & $2 \times 10^{18}$ \\
\hline
\end{tabular}

analyze main recombination center's location influence on the cells temperature sensitivity, two types of structures have been modeled for each cell:

- a structure without interface states at the solar cell's junction. The main recombination centers are located in the bulk;

- a structure representing a solar cell with interface state at the junction. For these cells, the recombination mechanism at the interface dominates those in volume.

Defects energy distribution are introduced by two Gaussian for the a-Si:H (i)/ $\mu c-S i(n)$ and $\mu c-S i(n) / a-S i: H$ (i) hetero-junction. For the case of CIGS (p)/CdS(n), $\mathrm{TiO}_{2} /$ Perovskite or Perovskite/Spiro-HTM interfaces, uniform donor defects energy distribution is used. The typical recombination mechanism in thin film solar cells is
Shockley-Read-Hall (SRH) one $[9,10]$. This mechanism is used for the device simulation in SCAPS by entering the defect density $\left(N_{d}\right)$. The $\mathrm{SRH}$ recombination rate $\left(R_{\mathrm{SRH}}\right)$ is given by the following equation:

$$
R_{\mathrm{SRH}}=\frac{\left(n p-n_{i}^{2}\right)}{\tau_{p 0}\left[n+n_{i} \exp \left(\frac{E_{d}-E_{i}}{k_{B} T}\right)\right]+\tau_{n 0}\left[p+n_{i} \exp \left(\frac{E_{i}-E_{d}}{k_{B} T}\right)\right]}
$$

where

$$
\tau_{n 0}=\frac{1}{\sigma_{n} \nu_{t h} N_{d}} \text { and } \tau_{p 0}=\frac{1}{\sigma_{p} \nu_{t h} N_{d}}
$$

depend on thermal velocity $\left(v_{t h}\right)$, defect density $\left(N_{d}\right)$ located at energy $E_{d}$ and capture cross section $\left(\sigma_{n, p}\right)$. $n, p$ are electron, hole concentrations, respectively and $n_{i}$ the intrinsic charge carriers concentration. 


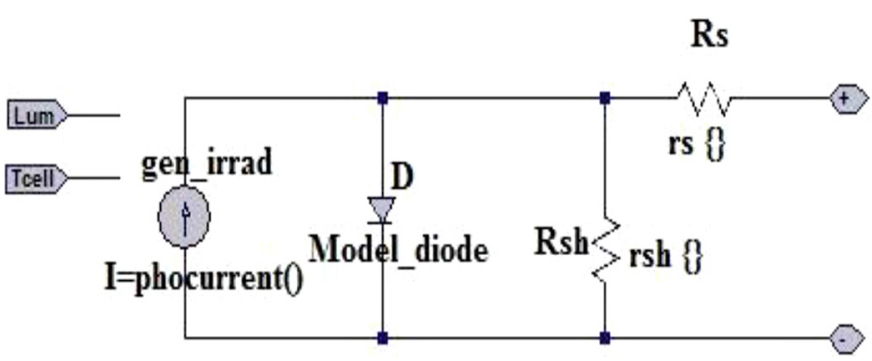

Fig. 2. LTSpice model.

In this work, we also consider the contribution of the recombination mechanism to the reduction of the PV cells performance. The defect density is considered as a variable parameter during the simulation in order to have cells with different efficiencies. However, due to the cell's specificity, the defect density introduced to have the same efficiency for different cells is different.

Furthermore, the performance ratios of the modeled cells were evaluated according to the location of the main recombination centers and compared to those of crystalline silicon-based technologies. We use for this purpose, the LTSpice model of modules (Fig. 2) where $r_{s}\{\}$ and $r_{s h}\{\}$ are the parametric values of $R_{s}$ and $R_{s h}$, respectively. The mathematical model used is given by equation (2). The input variables are cell's electrical parameters (series $\left(R_{s}\right)$ and shunt $\left(R_{s h}\right)$ resistances, ideality factor $(n)$, and saturation current $\left(I_{0}\right)$.), Standard Test Conditions and climatic data (ambient temperature, irradiation and wind speed). The influence of sub-Saharan African climatic conditions on solar module has been studied by Kata et al. [11]. The module electrical parameters are obtained from the hybrid algorithm based on analytical and LevenbergMarquardt algorithms that we developed and validated [12] (Fig. 3). The temperature and sun irradiation used for simulation were measured in real condition (sub-Saharan condition) at the same time by temperature sensor PT100 and a pyranometer.

$$
\begin{aligned}
& I=I_{p h}-I_{0}\left[\exp \left(\frac{q V}{n K_{B} T}\right)-1\right]-\frac{V+R_{s} I}{R_{s h}} \\
& I_{\text {oin }}=\frac{I_{\text {phin }}-\frac{V_{\text {ocref }}}{R_{\text {shin }}}}{\exp \left(\frac{q V_{\text {ocref }}}{n K_{B} T_{\text {ref }}}\right)-1} \\
& R_{\text {shin }}=\frac{\left(V_{\text {mref }}+I_{\text {mref }} R_{\text {sref }}\right)}{I_{\text {phin }}-I_{\text {mref }}-I_{\text {oin }}\left(\exp \left(\frac{q\left(V_{\text {mref }}+I_{\text {mref }} R_{\text {sin }}\right)}{n K_{B} T_{\text {ref }}}\right)-1\right)} \\
& R_{\text {sin }}=R_{\text {soin }}-\frac{1}{\frac{q}{n K_{B} T_{\text {ref }}} I_{\text {oin }} \exp \left(\frac{q V_{\text {ocref }}}{n K_{B} T_{\text {ref }}}\right)} \\
& I_{\text {phin }}=\frac{R_{\text {sin }}+R_{\text {shin }}}{R_{\text {shin }}} I_{\text {scref }}
\end{aligned}
$$

$$
\begin{aligned}
& R_{\text {soin }}=\frac{V_{\text {ocref }}-V_{\text {mref }}}{2 I_{\text {mref }}} \\
& R_{\text {shoin }}=\frac{V_{\text {mref }}}{I_{\text {scref }}-I_{\text {mref }}}
\end{aligned}
$$

where $K_{B}$ is the Boltzmann constant, $q$ is the charge of electron, $R_{s i n}$ is the initial series resistance, $R_{\text {shin }}$ is the initial shunt resistance, $R_{\text {soin }}$ is the reciprocal slope of initial $I-V$ curve at open-circuit condition, $I_{p h i n}$ is the initial photo-generated current, $I_{o i n}$ is the initial dark saturation current, $V_{\text {ocref }}$ is the reference open circuit voltage, $V_{\text {mref }}$ is the reference maximum output voltage, $I_{m r e f}$ is the reference maximum output current, $I_{\text {scref }}$ is the reference short circuit current and $T_{r e f}\left(25^{\circ} \mathrm{C}\right)$.

\section{Results and discussion}

The temperature variation leads to a slight increase in the short-circuit current $\left(I_{s c}\right)$ while the open circuit voltage $\left(V_{\text {oc }}\right)$ is much more affected by this variation. Therefore, knowing the cell Voc temperature sensitivity, one can evaluate the cell's temperature sensitivity. At the open circuit, generated currents and recombination currents are balanced. The open circuit voltage of the cell is written as [13]:

$$
V_{o c}=\frac{n K_{B} T}{q} \ln \left(\frac{I_{s c} \eta\left(V_{o c}\right)}{I_{0}}\right)
$$

where $I_{0}=I_{00} e^{E_{a}} /{ }_{n k T}$ and $E_{a}$, activation energy.

We assume a linear variation of $E_{a}$ in cell operating temperature range:

$$
E_{a}=E_{a 0}+T \frac{d E_{a}}{d T} .
$$

Differentiating equation (9) gives equation (11) similar to that obtained in reference [5]:

$$
\begin{gathered}
\frac{d V_{o c}}{d T}=-\frac{\frac{E_{a 0}}{q}-V_{o c}+\zeta \frac{n K_{B} T}{q}}{T} \\
\zeta=\frac{d \ln \left(I_{s c}\right)}{d \ln T}+\frac{d \ln \left(\eta\left(V_{o c}\right)\right)}{d \ln T}-\frac{d \ln \left(I_{00}\right)}{d \ln T} .
\end{gathered}
$$

$E_{a 0}$ and $V_{o c}$ depend on the location of the recombination mechanism. Figures $4 \mathrm{a}-4 \mathrm{c}$ show that the cell junction activation energy depends on the location of the recombination mechanism:

- If the main recombination centers are located at the junction's interface and the band off-set $\left(\Delta E_{c}\right)$ is less than zero (cliff), then

$$
E_{a}=\min \left(E_{g 1}, E_{g 2}\right)+\Delta E_{c} .
$$

$E_{g 1}$ and $E_{g 2}$ are the band gaps of the semiconductors forming the cell's junction. Due to a negative conduction band offset, the value of electron energy at interface and thus the electron concentration at the interface is increased. 


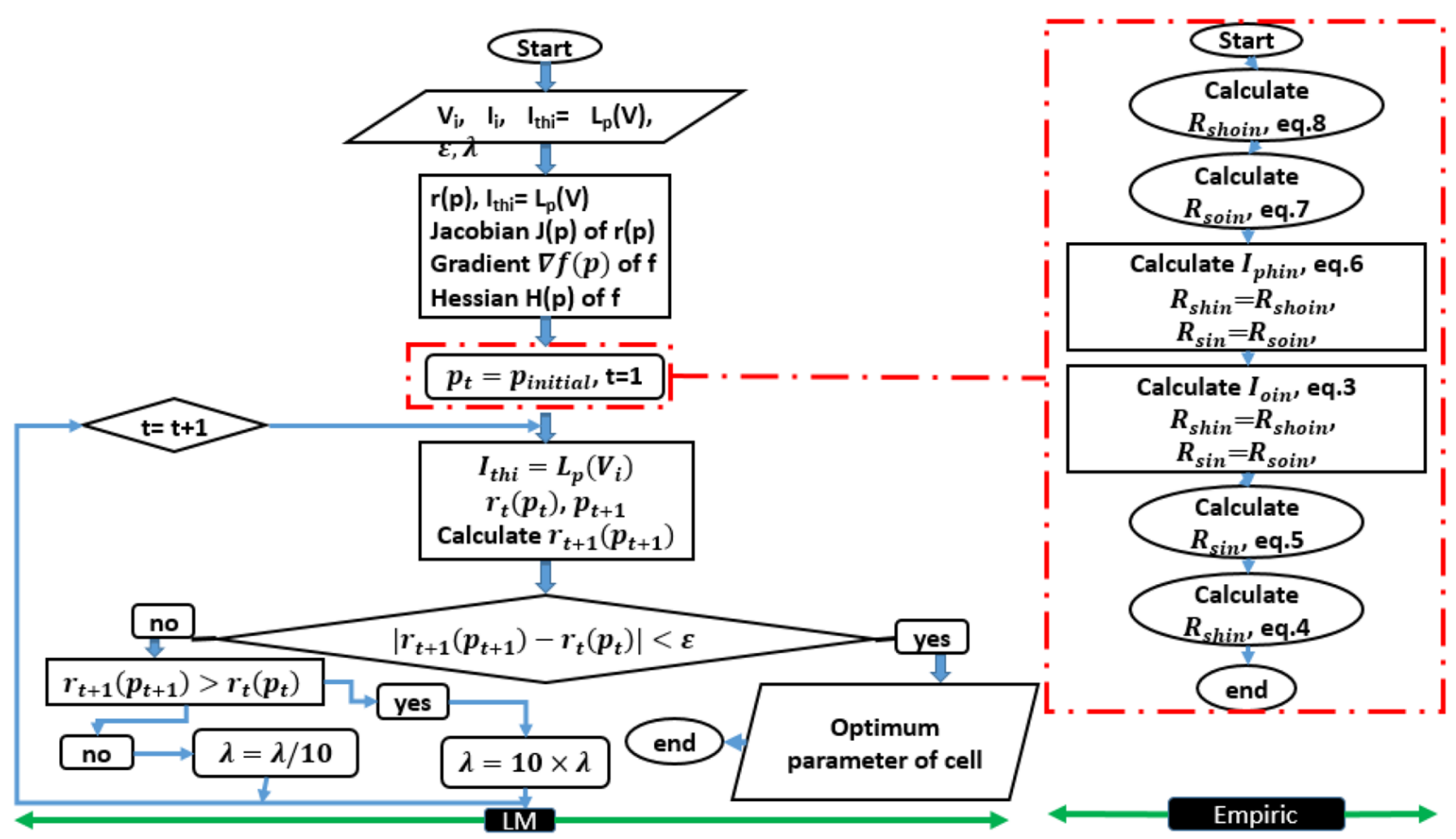

Fig. 3. Organigram of the cell parameters extracting program.
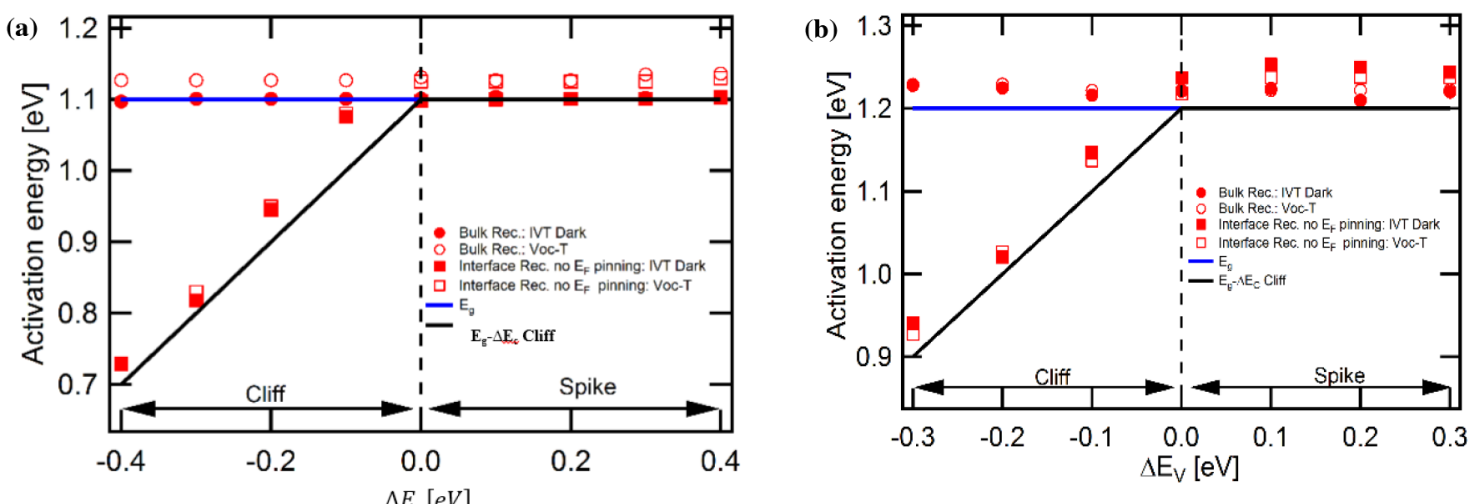

(c)
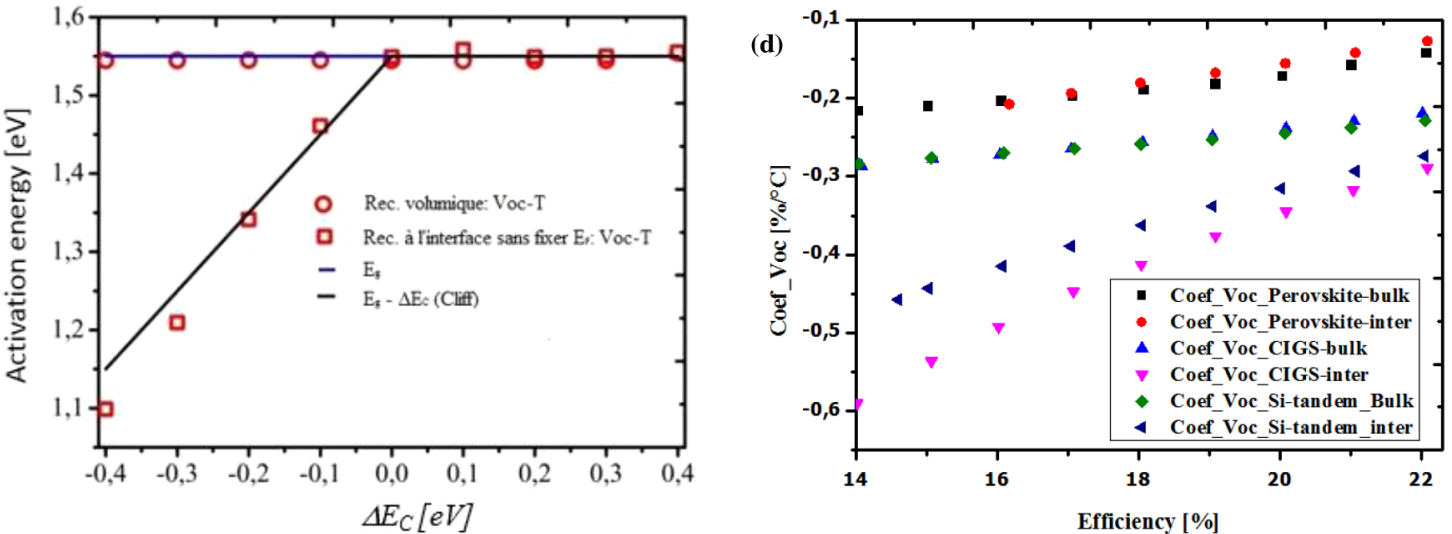

Fig. 4. The summary of the results of the energy of the two methods for activating the tandem amorphous/microcrystalline (a), CIGS (b) and Perovskite (c) and (d) variation of the open circuit voltage temperature coefficient as a function of efficiency. 

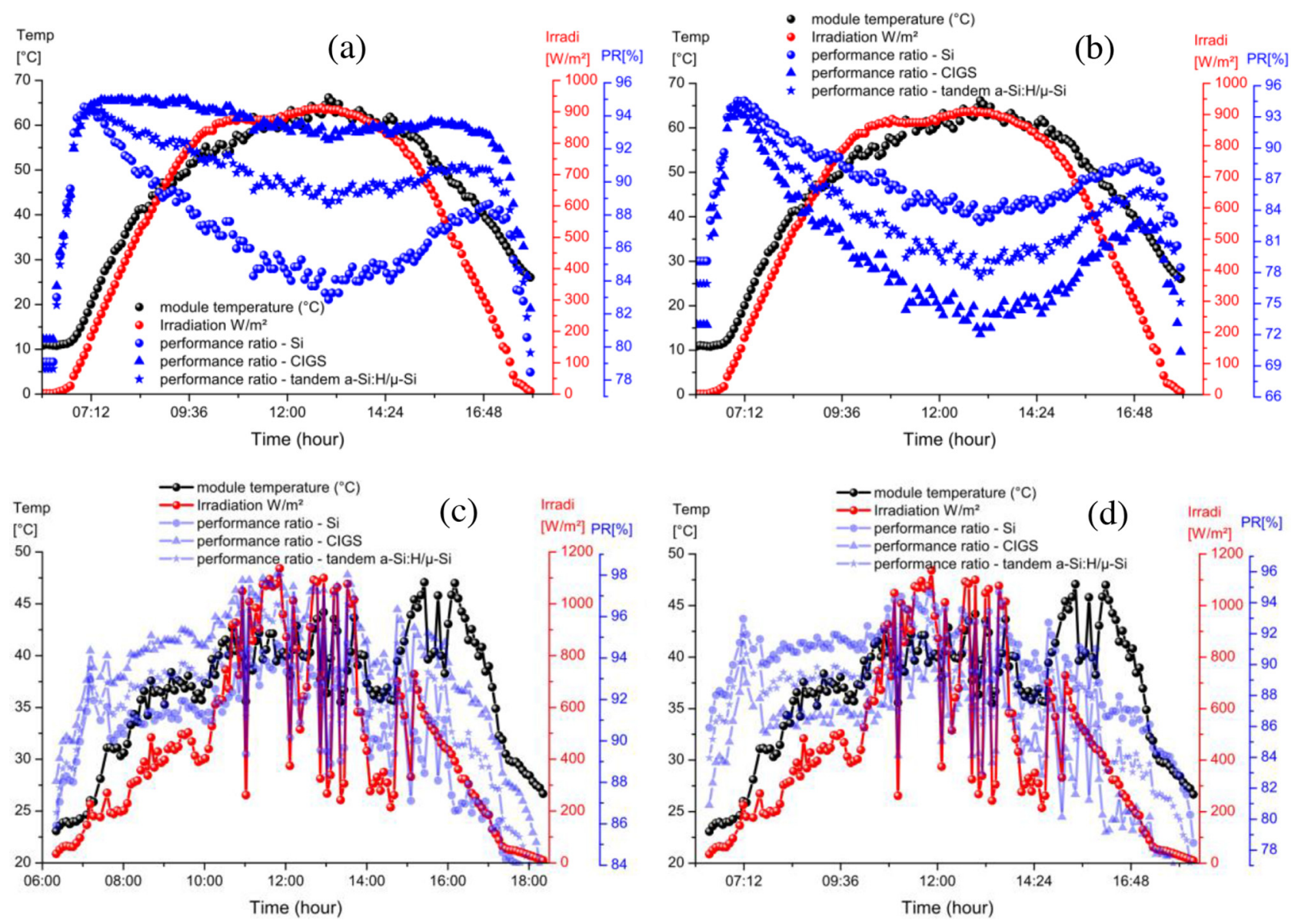

Fig. 5. Daily evolution of the PR of different photovoltaic modules with: main recombinant centers in volume for a clear day (a) and cloudy day (c), main recombinant centers at the interface for a clear day (b) and cloudy day (d).

- Otherwise, if the main recombination centers are located in the volume of the absorber or the band off-set $\left(\Delta E_{c}\right)$ is upper than zero (spike), then

$$
E_{a}=\min \left(E_{g 1}, E_{g 2}\right) .
$$

Sheer [13] derived the same valuable rules for activation energy.

Figure 4d presents cells' open circuit voltages temperature coefficient as a function of efficiency (defect density).

As mentioned elsewhere [5], the temperature coefficient of the open circuit voltage is explicitly sensitive to the recombination's mechanism. Among the simulated cells (Fig. 4), the perovskite one is less sensitive to temperature variations regardless of the location of the recombination centers. The CIGS and silicon tandem cells are not only relatively sensitive to temperature variation but also this sensitivity becomes more important when the recombination centers are located at the interface of the cell. Their efficiencies are low for the higher density of recombination centers. Due to lattice mismatch or defect segregation of cell's layers, the thin film solar cells present a high risk of the presence of the recombination center at their interface junction. So, reducing defect density at the thin films solar cells interface would contribute in reducing their temperature sensitivity.
Even if, perovskite is interested in photovoltaics, very few modules based on this cell technology have been tested in outdoor conditions [14]. Due to the non-maturity of the perovskite technology, their modules will not be studied in the rest of this work.

The performance ratios (PR) of the different modules under conditions of a cloudy day with cell temperatures below $50{ }^{\circ} \mathrm{C}$ and a clear sky day with temperatures around $70{ }^{\circ} \mathrm{C}$ are simulated. The different modules were simulated for cells with $18 \%$ of efficiency. The results are shown in Figure 5. This performance indicator is given by equation (14).

$$
\mathrm{PR}=\frac{P_{m p}}{P_{m p, S T C}} \times \frac{I_{s c, S T C}}{I_{s c}} .
$$

The performance ratios are much lower for modules with main recombination centers at the interface of their cells. Otherwise, the thin film (tandem and CIGS) modules with main recombination centers in the volume of their cells lose performance less quickly compared to those with recombination at the interface. For the same efficiency, crystalline silicon module performance ratios become higher than thin film module with recombination at the cells interface. 

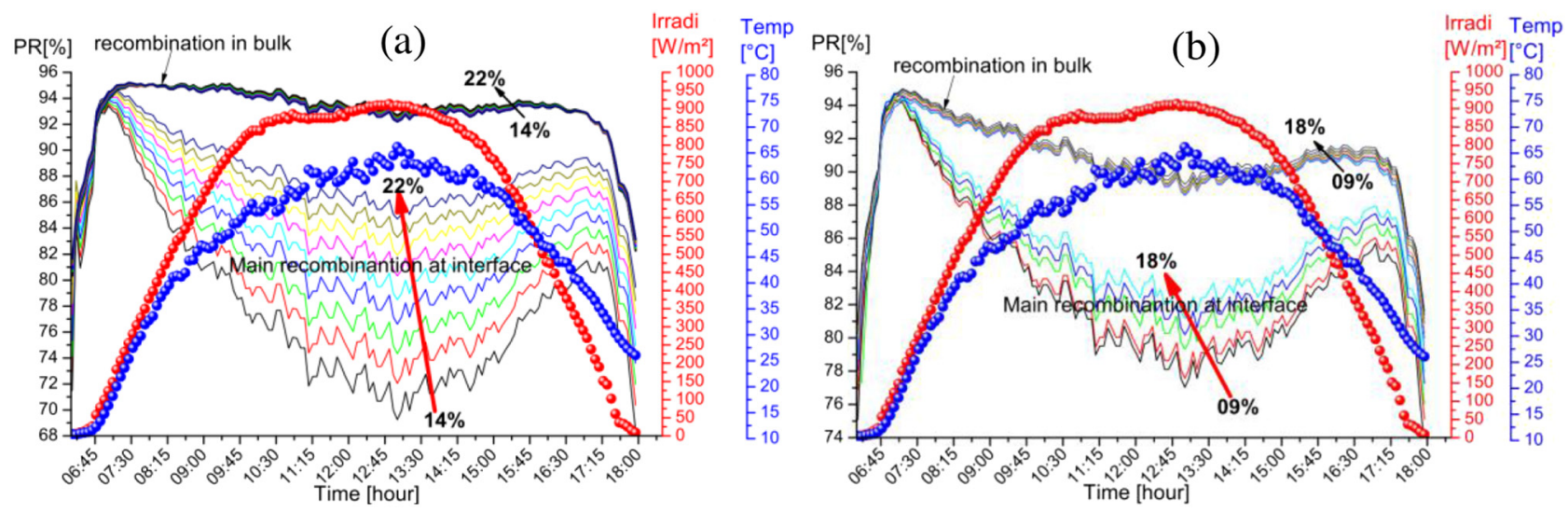

Fig. 6. Performance ratio of different efficiency of CIGS modules (a) and silicon tandem (b).

The results of Figure 6 show that the performance ratios of the thin film cells with main recombination mechanisms at the heterojunction interface are more degraded. This figure further illustrates the importance of defect reduction at the interface of the thin film solar cell junction.

\section{Conclusion}

We have shown that the location of the main recombinant mechanisms impacts on cell temperature sensitivity. Among the simulated cells, the Perovskite cell is less sensitive to temperature variation. Although thin film cells have good performance ratios compared to crystalline silicon with the same efficiency, these performances drop quickly when their heterojunction interface have the main recombination centers. Thus, ensuring a good quality of the junction of thin film cells will contribute to the reduction of the temperature sensitivity of these cells.

We acknowledge the support of the African Centre of Excellency in Mathematics, Informatics and TIC (CEA-MITIC) and Laboratory of Solar Energy and Energy Saving (LESEE) of International Institute of water and Environment Engineering (2iE).

\section{Author contribution statement}

This paper is result of a research done in LEITER laboratory by N. Kata, a member of LEITER. The data analysis is done by N. Kata under the supervision of D. Diouf and A. Darga. Professor A. Seïdou Maïga is the director of laboratory and oversaw the entire study of the paper.

\section{References}

1. OXFAM, in Le défi énergétique en Afrique subsaharienne: Guide pour les défenseurs et les décideurs, Première partie, (2017), pp. 41-42
2. F. Ndiaye, M. Sène, M. Beye, A.S. Maiga, Effects of climatic conditions on a polycrystalline photovoltaic Module in Niger, in International Conference on Composite Materials and Renewable Energy Applications (ICCMREA), 2014

3. A. Ndiaye, C.M.F. Kébe, A. Charki, Degradation evaluation of crystalline-silicon photovoltaic modules after a few operation years in a tropical environment, Sol. Energy 103, 70 (2014)

4. M. Green, General temperature dependence of solar cell performance and implications for device modelling, Prog. Photovolt. Res. Appl. 11, 333 (2003)

5. O. Dupré, R. Vaillon, M.A. Green, Physics of the temperature coefficients of solar cells, Sol. Energy Mater. Sol. Cells 140, 92 (2015)

6. T. Minemoto, M. Murata, Device modeling of perovskite solar cells based on structural similarity with thin film inorganic semiconductor solar cells, J. Appl. Phys. 116, 054505 (2014)

7. T. Carrere, R. Varache, D. Muñoz, J.P. Kleider, Insertion of a thin highly doped crystalline layer in silicon heterojunction solar cells: simulation and perspectives towards a highly efficient cell concept, J. Renew. Sustain. Energy 7, 011202 (2015)

8. A. Benmansour, Effect of CIGS thin layers on the efficiency of the photovoltaic cells with heterostructures (American Scientific Publishers, 2012)

9. R. Hall, Electron-hole recombination in germanium, Phys. Rev. 87, 387 (1952)

10. W. Shockley, W.T. Read, Statistics of the recombinations of holesand electrons, Phys. Rev. 87, 835 (1952)

11. N. Kata, D. Diouf, Y.M. Soro, A. Darga, A.S. Maiga, Temperature impact on dusty and cleaned photovoltaic module exposed in sub-Saharan outdoor conditions, EPJ Photovoltaics 9, 8 (2018)

12. N. Kata, Y.M. Soro, D. Diouf, A. Darga, A.S. Maiga, Module parameter extraction and simulation with LTSpice software model in sub-Saharan outdoor conditions, Afr. J. Environ. Sci. Tech. 12, 523 (2018)

13. R. Scheer, Activation energy of heterojunction diode currents in the limit of interfacere combination, J. Appl. Phys. 105, 104505 (2009)

14. https://www.lenouvelliste.ch/articles/valais/valais-central/ premiere-mondiale-a-l-epfl-de-sion-qui-invente-un-nouveautype-de-panneaux-photovoltaiques 2018 (accessed July 5, 2019)

Cite this article as: N. Kata, D. Diouf, A. Darga, A. Seidou Maiga, The effect of the recombination mechanisms location on the temperature sensitivity of thin-film photovoltaic cells, EPJ Photovoltaics 10, 8 (2019) 